\title{
Responses to Odors Mapped in Snail Tentacle and Brain by $\left[{ }^{14} \mathrm{C}\right]-2-$ Deoxyglucose Autoradiography ${ }^{1}$
}

\author{
RONALD CHASE \\ Department of Biology, McGill University, 1205 Avénue Docteur Penfield, Montréal, Quebec, H3A 1B1, Canada
}

\begin{abstract}
The method of 2-deoxyglucose (2-DG) autoradiography has been widely used to map functional neuronal systems in vertebrates, but in invertebrate species, where morphological dimensions favor its use, the applications have been minimal. This study uses $\left[{ }^{14} \mathrm{C}\right]-2-\mathrm{DG}$ to map the olfactory system of a terrestrial snail, Achatina fulica. The olfactory organ in the snail's tentacles bears a striking resemblance to the vertebrate olfactory mucosa. There are also complex neural structures in the tentacle and brain that are devoted to subsequent processing. These facts make the molluscan olfactory system a suitable complement to the traditional vertebrate and insect models in olfaction.

The experiments utilized intact snails in which one tentacle was exposed to a controlled odor environment while the contralateral tentacle was held in a retracted position. The dose of $\left[{ }^{14} \mathrm{C}\right]-2-D G(2 \mu \mathrm{Ci} / \mathrm{gm})$ was injected into the hemocele. Tissue processing involved freeze-substitution with acetone, dry sectioning, and the preparation of liquid film autoradiographs. Optical density measurements permitted quantitative comparisons between experimental conditions.

The natural odors of conspecific snails and of carrots elicited significantly more uptake of 2-DG in the exposed tentacle than in the unexposed tentacle and, in the exposed tentacle, significantly more label over the axons of the primary sensory neurons than was elicited by exposure to clean air. Amyl acetate and octanol were less effective. A small number of superficially placed sensory neurons were labeled in all stimulus conditions, including clean air, and may represent the mechanosensors. Stimulus-dependent labeling in the brain was limited to the procerebrum and included both neuropilar and cellular parts. In contrast to vertebrate and insect olfactory systems, there was no evidence of spatial coding for odor quality.
\end{abstract}

The method of 2-deoxyglucose (2-DG) autoradiography has been widely used to map functional pathways in vertebrate sensory systems. Applications of the method have been successful in nearly all of the sense modalities and in a variety of vertebrate animal

Received December 10, 1984; Revised May 1, 1985;

Accoptcd May 13, 1985

${ }^{1}$ This work was supported by grants from the Natural Sciences and Engineering Research Council of Canada and the Quebec Department of Education (FCAC). I am grateful to John Kaver for advice on methods, lan Chin-Yee for collaboration in pilot studies, Barbara Tolloczko for technical assistance, Robert Lamarche for photography, Rhonda Amsel for statistics, and Gerry Pollack and Barbara Tolloczko for criticism of the manuscript. groups (Plum et al., 1976; Sharp et al., 1981). By contrast, there have been hardly any applications of 2-DG autoradiography to invertebrate sensory systems (Buchner et al., 1979; Buchner and Buchner, 1983; Rodrigues and Buchner, 1984). This may reflect, in part, the occurrence in some invertebrate species of alternate forms of energetic metabolism which may limit the effectiveness of the method or complicate the interpretation of its results. Insects, for exarriple, make use of trehalose and fatty acids, in addition to glucose and glycogen, as intermediate sources for high energy phosphates (Buchner and Buchner, 1983).

An additional limitation has been the requirement for autoradiographic techniques which yield high resolution, owing to the small dimensions of invertebrate neural structures. l lowever, the recent introduction of several technical innovations has considerably improved the expected level of resolution (Sejnowski et al., 1980; Lancet et al., 1982; Hammer and Herkenham, 1984). Notwithstanding the aforementioned obstacles, invertebrates are excellent candidates for the application of 2-DG methodology. Their small size provides an economy of use; the nervous structures are often small enough to be visualized in toto on a single tissue section; and the presence of at least some exceptionally large neurons offers the opportunity to study the metabolism of single, identifiable cells (Scjnowski ct al., 1980; Rcingold et al., 1981; Wei, 1983)

In the present investigation, 2-DG autoradiography was used to study the olfactory system of a terrestrial snail. This animal, as do all gastropod molluscs (Croll, 1983), uses olfaction as the principal sensory modality for perception at a distance (Chase et al., 1978; Chase and Croll, 1981; Chase, 1982). Several recent reports have described associative conditioning to odors in gastropod molluscs (Croll and Chase, 1980; Sahley et al., 1981; Alexander et al., 1983), thus raising the possibility of combined neural-behavioral investigations into the mechanisms of learning and memory. If studies with such systems are to be conclusive, however, it will be necessary to learn much more about the molluscan olfactory system than is presently known. A further incentive for new information about molluscan olfaction is the need to develop alternative models for the study of olfaction, to complement the current, almost exclusive, use of vertebrate and insect species. In this regard, the striking histological resemblance between the vertebrate olfactory mucosa and the olfactory organ in the tentacles of snails and slugs is especially noteworthy ( $R$. Chase, manuscript in preparation). The extensive use of 2-DG autoradiography to reveal functional details of the vertebrate olfactory system (Stewart et al., 1979; Jourdan et al., 1980; Teicher et al., 1980; Nathan and Moulton, 1981; Lancet et al., 1982) has encouraged a parallel approach in the snail.

The experiments reported here had as their primary objective the identification of neural tissues responsive to environmental odors. The search for such tissues was limited to the specialized epidermal and neural apparatus at the tip of the posterior (optic) tentacles (Wright, 1974; Chase and Kamil, 1983; Croll, 1983; Chase and 
Tolloczko, 1985), and to the cerebral ganglion (brain) with which the tentacle ganglion is connected via a long nerve. However, epithelium and muscle were also examined, in addition to the neural structures, because recent studies have implicated some non-neural cell types in olfactory processes (Price, 1984).

A perceptible difference in odor quality must produce, at some level in the nervous system, a difference in response. In vertebrates, the use of 2-DG autoradiography has revealed odor-dependent variations in response that support the hypothesis of a spatial code for odor quality (Stewart et al., 1979; Jourdan et al., 1980; Kauer, 1980; Mackay-Sim and Kubie, 1981; Nathan and Moulton, 1981). In the present study, odor-dependent variations in neural response were investigated using both qualitative and quantitative criteria. The odors used as stimuli were selected on the basis of their substantial differences and because of their known effectiveness in eliciting orientation behaviors in the experimental animal (Chase et al., 1978; Croll and Chase, 1980; Chase, 1982).

\section{Materials and Methods}

Specimens of the terrestrial snail Achatina fulica weighing 9 to $21 \mathrm{gm}$ were selected as siblings from a single clutch of eggs produced in laboratory culture (Pawson and Chase, 1984). The snails were starved for 6 days. Eighteen hours before the 2-DG experiments, each animal was injected with $0.2 \mathrm{ml}$ of $0.5 \%$ succinylcholine chloride to produce immobilization. The skin at the base of the left posterior tentacle was then sutured together so that the naturally retracted tentacle was incapable of extension following recovery

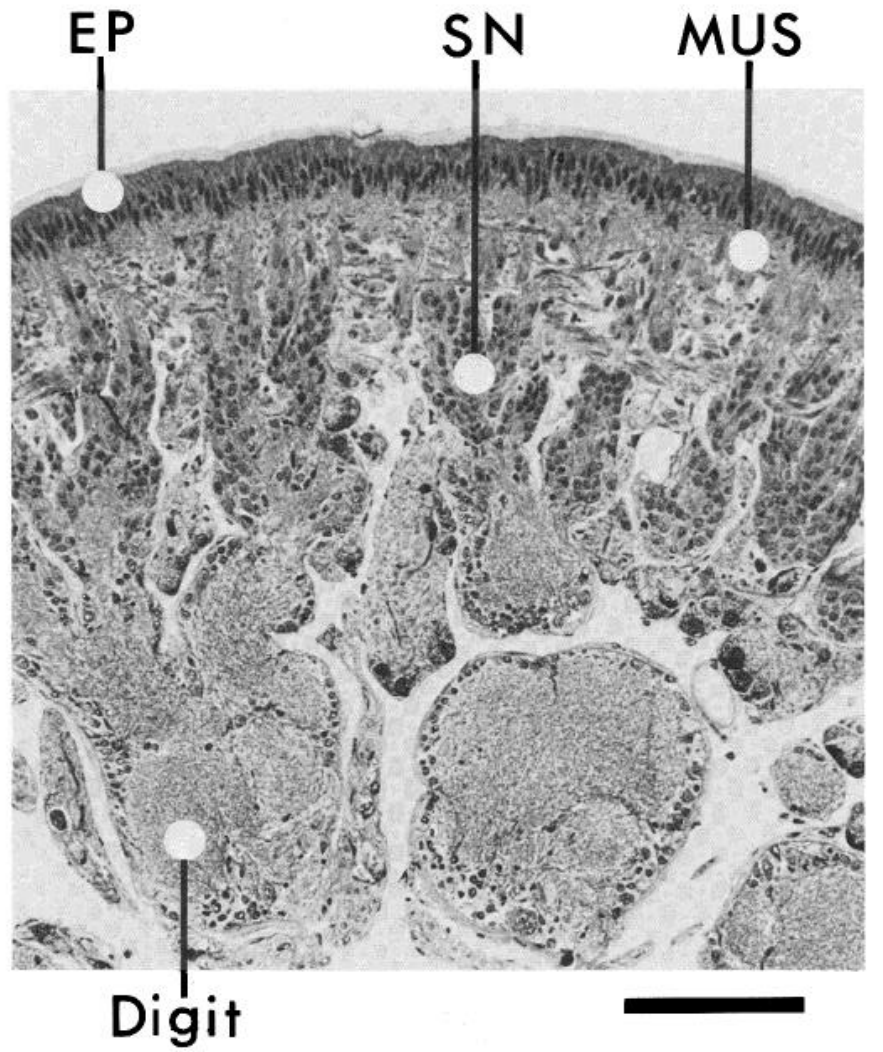

Figure 1. Histological appearance of tentacle olfactory organ in crosssection. The white dots mark the positions and approximate sizes at which optical density measurements were made. EP, epithelium; $S N$, sensory neuron somata; MUS, muscle. The bipolar sensory neurons are collected in lobules, which merge ventrally with the digits, as seen at the left. The dendrites of the sensory neurons extend through the muscle and epithelium to reach the superficial mucus cover. Some of the receptor axons synapse in the digits; others travel to the tentacle ganglion or to the procerebrum. The digits contain local interneurons and centrifugal fibers, in addition to the sensory afferents. Section thickness is $1 \mu \mathrm{m}$; toluidene blue stain. Scale bar, $100 \mu \mathrm{m}$. from the surgery (typically, $1 \mathrm{hr}$ ). The functional capacity of the sutured tentacle was not impaired by this procedure, as evidenced by behavioral tests with small pieces of carrot using a few animals in which the suture tore free on the morning of experimentation.

Doses of 2-[1-14 C]-deoxy-D-glucose (New England Nuclear, NEC-495A, 51 $\mathrm{mCi} / \mathrm{mmol}$ ) at $2 \mu \mathrm{Ci} / \mathrm{gm}$ of body weight were injected into the hemocele via the skin at the juncture of the foot and the visceral hump. Immediately following an injection, a single animal was placed in a 1-liter flask together
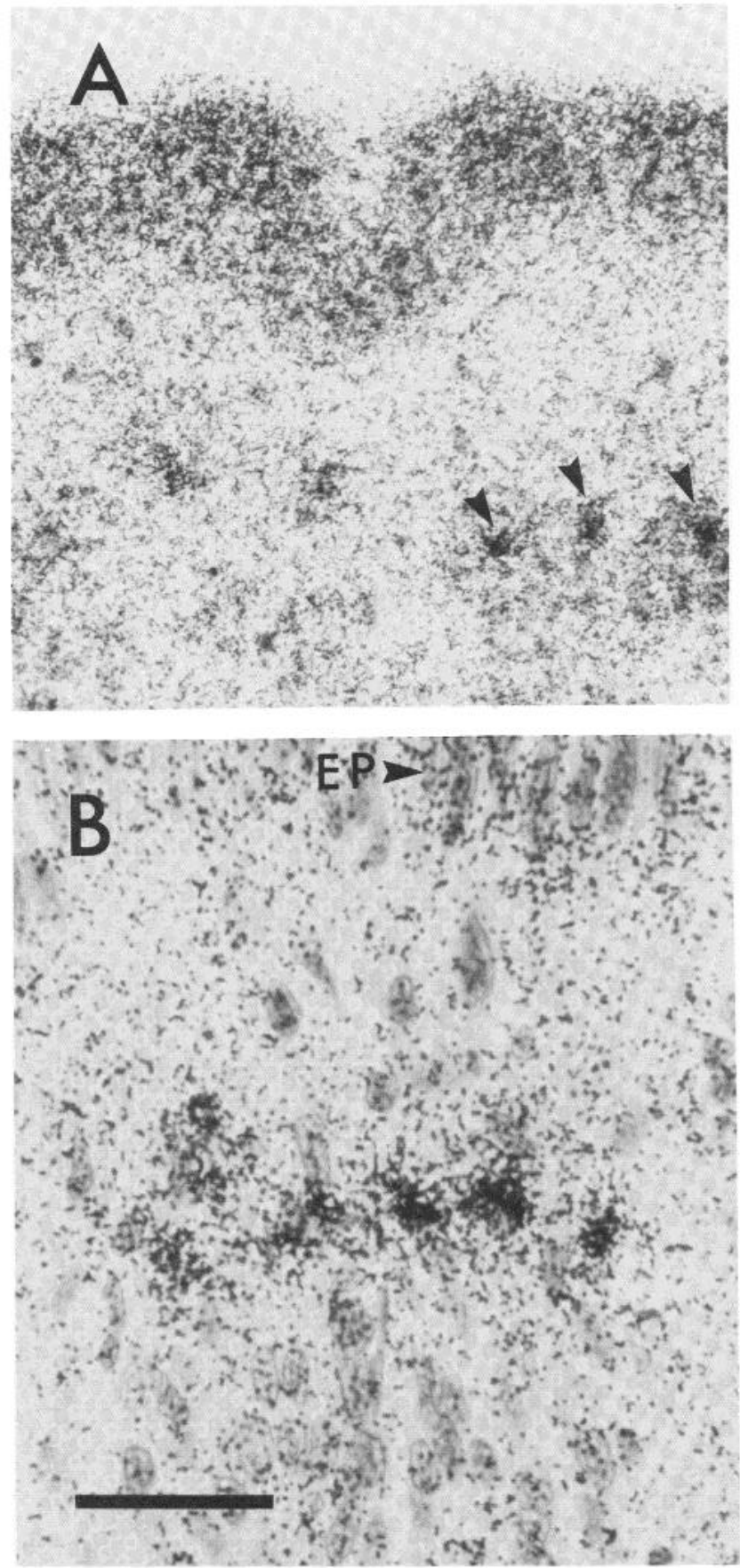

Figure 2. High resolution autoradiographic labeling of epithelium and sensory neurons. $A$, Intense labeling is limited to convoluted epithelium (top) and a few sensory neurons (arrowheads). B, Higher magnification view showing lightly labeled epithelial cells $(E P)$ and more heavily labeled sensory neurons. In both $A$ and $B$, the labeled neurons lie at superficial positions within the lobules containing other, similar neurons. Between the epithelium and the sensory neurons lies a layer composed of muscle, glands and stray sensory neurons. Scale bar: $A, 40 \mu \mathrm{m} ; B, 20 \mu \mathrm{m}$. 
with approximately $50 \mathrm{ml}$ of water (for moisturization). Total air flow through the flask was maintained at $200 \mathrm{ml} / \mathrm{min}$. Two animals were used for each of five stimulus conditions. In the "clean air" condition, air was supplied by a cylinder containing "Zero Gas" (Canadian Liquid Air) which had total hydrocarbon impurities $<3 \mathrm{ppm}$. The odor stimuli were produced by filtering a supply of compressed ambient air and then passing the air through an appropriate odor source. The source for the "snail" stimulus was a collection of 12 active snails ( $A$. fulica) held in a 1-liter flask. The "carrot" stimulus was created by saturating an air space with the vapors from minced fresh carrot root. Octanol and amyl acetate odors were delivered as 1:10 dilutions of the salurated vapor by a previously described method (Chase, 1982)

The snails were sacrificed after $4 \mathrm{hr}$ of stimulus exposure. The posterior tentacles were dissected and the olfactory organ at the tip (the "sensory pad"), together with the associated neural ganglion, was pinned flat to a small Sylgard chip for processing. The brain was cleaned of overlying tissue and similarly prepared. Subsequently, tissue processing and preparation of autoradiographs followed the procedures described by Sejnowski et al. (1980; see also Lancet et al., 1982). Briefly, tissue was frozen in Freon 23 , freeze-substituted in anhydrous acetone at $-70^{\circ} \mathrm{C}$ for $48 \mathrm{hr}$, and embedded in Araldite to which $1 \%$ silicone fluid (Dow Corning) had been added. The brain was bisectcd with a bladc while semi hardened. Sections were cut at $3 \mu \mathrm{m}$ thickness. Although the entire olfactory organ was examined for qualitative results in some specimens, for quantitative work only the \pm 150 $\mu$ min of the mid-length of the sernsury pad was used (aboul $20 \%$ of the pad). The brain was sectioned in its entirety. All sections were adhered anhydrously to glass slides. The slides were dipped in NTB-2 nuclear emulsion (Eastman Kodak), exposed tor 4 weeks at $4^{\circ} \mathrm{C}$, developed, and stained with $0.1 \%$ toluidene blue in $1 \%$ borax.

Optical density measurements were obtained using a Leitz Orthoplan microscope fitted with a Leitz MPV1 unit. The tungsten light source was filtered through a 415-nm narrow band filter (Schott; half-width, $11 \mathrm{~nm}$ ) in order to compensate for the toluidine blue stain. A graduated interference filter was adjusted for maximum transmission sensitivity. Residual density from the stain was further compensated for by normalizing all measurements of autoradiographs against a sample of similar measurements obtaincd from stained, but undipped, sections.

Measurements were obtained from six sections per tentacle, sampled at intervals of $28 \mu \mathrm{m}$. The measurements were made through a circular aperture of diameter $19 \mu \mathrm{m}$, viewed at $\times 500$ magnification. Figure 1 shows the positions at which measurements were made. Two separate measurements were made in the digits, one trom the bundles of sensory neuron axons and a second from the adjacent neuropil. Although it was not usually possible to discern structural details under the conditions of optical density measurement, independent examination of alternate dipped and undipped sections (Fig. 3), as well as observation of many dipped sections in several focal planes, confirmed that the foci of greatest optical density consistently overlay the sensory axons. The procedure in practice, therefore, was to locate the region within the digits of greatest apparent optical density and to assume that measurements taken over this region were measurements overlying sensory neuron axons.

The five measurements obtained from each section were normalized against non-tissue background measured on the same section. The resulting values were analyzed by a computer using the Statistical Package for the Social Sciences.

\section{Results}

Struclures labeled in the lentacle. The histological appearance of the snail olfactory organ is illustrated by the cross-section shown in Figure 1. The epidermis comprises several cell types which, as in the vertebrate olfactory mucosa, are segregated by relative depths from the epithelial surface (for details, see Wright, 1974; Chase and Kamil, 1983; Chase and Tolloczko, 1985). The receptors are primary sense cells, hereafter referred to as sensory neurons. The autoradiographic signal was, in some tentacles, essentially confined to a single lamina, as for example, the epithelium (Fig. 2A). The resolution of the autoradiography was sometimes sufficient to discern individually labeled muscle fibers, protein glands, and sensory neurons. In other cases, when the labeling was heavy and the underlying tissue stain was light, the tight packing of the sensory neurons limited the resolution to small clusters of cells (Fig. $2 B$ ). The dimensions of the sensory neui on somata are approximately $6 \mu \mathrm{m} \times 8 \mu \mathrm{m}$ (nucleus, $\sim 4 \mu \mathrm{m} \times 6 \mu \mathrm{m})$.
The number of labeled sensory neuron somata in each tentacle was estimated by counting labeled cells (grain density at least 5 times background) in a sample of sections (Table l). The frequency of labeling was always greater in the exposed tentacle, as compared with the unexposed tentacle, but there were no significant differences between stimulus conditions. The absolute number of labeled sensory neurons was extremely small in relation to the total population, with only about $3 \%$ of the cells labeled, on average, in an exposed lerilacle. A striking feature of these results was the finding that nearly all of the labeled sensory neurons were situated in the most superficial aspect of the sensory lobules (Table I, Fig. 2B).

In the majority of tentacles, the most dense and the most focused label appeared in the digitary extensions of the tentacle ganglion. The ganglion itself always had a uniformly light label. The digits have a cross-sectional structure typical of invertebrate ganglia, with interneurons around the circumference and a central neuropil (Fig. 3). They are a conduit for the transmission centrally of afferent signals. By examining alternately dipped and undipped sections, it was possible to identify the focal labels in the digits as belonging to bundles of sensory neuron axons (analogous to the filia olfactoria of the vertebrate nose). These fibers (diameters $<0.5 \mu \mathrm{m}$ ) descend from the lobules of sensory neurons overlying the digits (Fig. 3, C and $D$ ) and then bend to course centripedally along the length of the digits (shown in cross-section in Fig. $3, A$ and $B$ ). Many of the axons, but not all of them, form synapses in the digits (Demal, 1955; Chase and Kamil, 1983). The digit foci were often sharply circumscribed and, in some cases, only a portion of an otherwise homogeneous fiber bundle was labeled (Fig. $3 E$ )

Stimulus-dependent labeling in the tentacle. The effects of sensory stimulation upon 2-DG uptake in the tentacle are shown in Figure 4. These micrographs illustrate the range of observed patterns and densities of the autoradiographic label. In order to determine whether the small foci in the digits, which are variously placed, form a spatial pattern characteristic for each odor, all exposed tentacles were reconstructed in three dimensions by making drawings from selected sections. Comparisons between different stimulus conditions, and between replications of the same stimulus condition, failed to reveal any dependency of the locations of digit foci on stimulus

TABLE ।

Occurrence of labeled sensory neurons following an injection of $\left[{ }^{14} \mathrm{C}\right]-2-D G$

The values are mcans $\pm S D$ for single tissue scctions. The sample size is 12 sections (two animals) in all cases. The observation error is about $10 \%$, or less, depending on tissue quality. A typical section contains about 600 sensory neurons; there are about 100,000 per tentacle. Superficial and deep refer to positions with respect to the epithelial surface; cells were judged to be superficial if they lay approximately within the upper $5 \%$ of their lobule.

\begin{tabular}{lccc}
\hline \multicolumn{1}{c}{ Stimulus Condition } & Superficial & Deep & Total \\
\hline Clean air & & & \\
$\quad$ Exposed tentacle & $7.6 \pm 6.7$ & $1.4 \pm 1.7$ & $0.0 \pm 8.1$ \\
$\quad$ Unexposed tentacle & $0.1 \pm 0.3$ & 0 & $0.1 \pm 0.3$ \\
Snails & & & \\
$\quad$ Exposed tentacle & $11.4 \pm 3.8$ & $1.9 \pm 2.3$ & $13.3 \pm 4.2$ \\
$\quad$ Unexposed tenlacle & 0 & $0.1 \pm 0.3$ & $0.1 \pm 0.3$ \\
Carrot & & & \\
$\quad$ Exposed tentacle & $15.2+8.8$ & $4.0+3.4$ & $19.2 \pm 11.2$ \\
Unexposed tentacle & $1.7 \pm 3.0$ & $0.3 \pm 0.9$ & $2.0 \pm 3.0$ \\
Octanol & & & \\
$\quad$ Exposed tentacle & $13.2 \pm 4.5$ & $2.6 \pm 2.1$ & $15.8 \pm 5.0$ \\
Unexposed tentacle & $0.2 \pm 0.6$ & $0.1 \pm 0.3$ & $0.3 \pm 0.7$ \\
Arryl acelate & & & \\
$\quad$ Exposed tentacle & $9.3 \pm 8.5$ & $3.0 \pm 2.5$ & $12.3 \pm 10.1$ \\
$\quad$ Unexposed tentacle & $0.1 \pm 0.3$ & 0 & $0.1 \pm 0.3$ \\
\hline
\end{tabular}



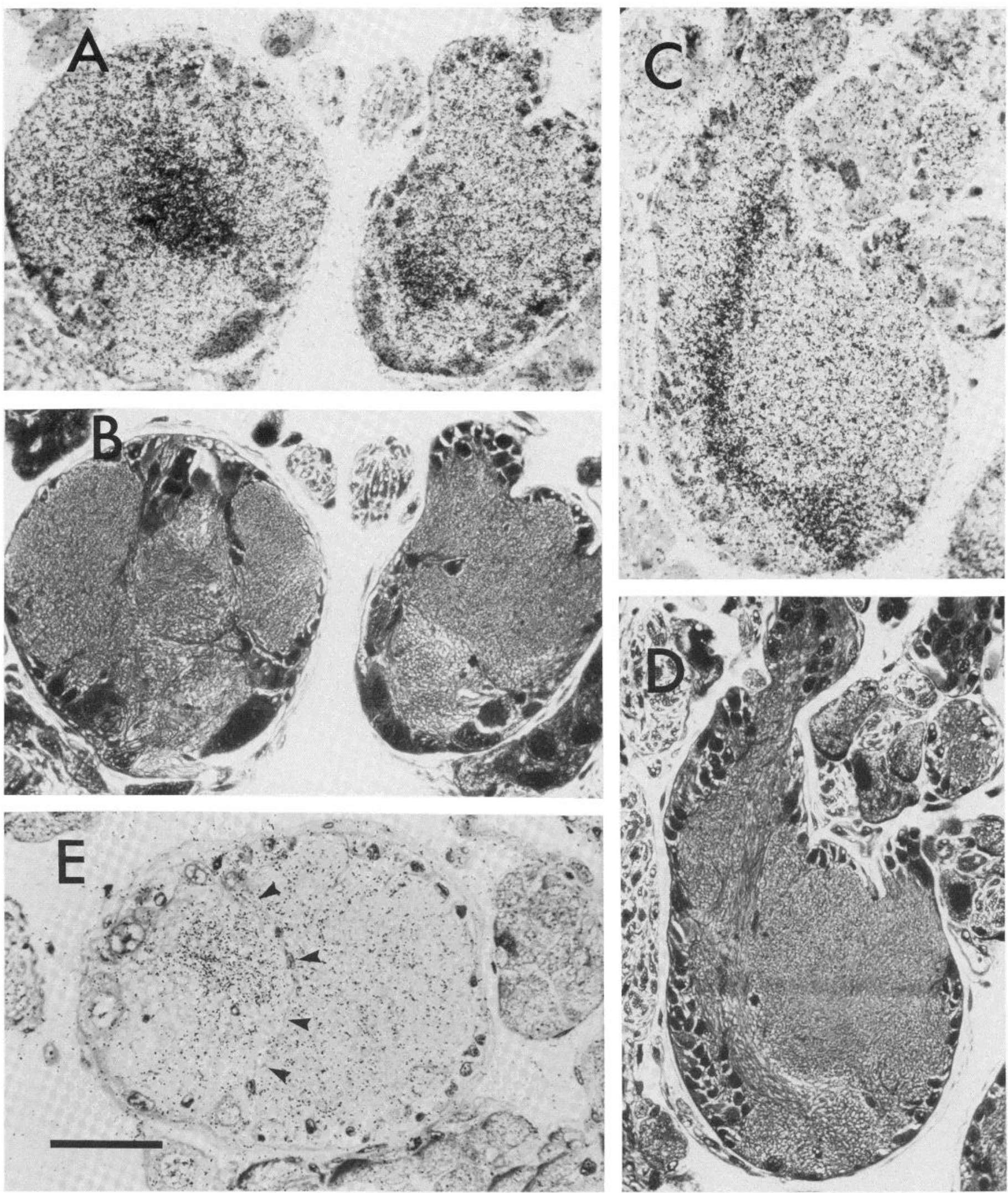

Figure 3. Uptake of 2-DG by sensory neuron axons in tentacle digits. A, Adjacent digits each have autoradiographic foci. $B$, Histological section paired with $A$ shows that heaviest label is confined to areas containing cross-sections of fiber bundles; note the glial encirclement of the bundle at the left. $C$ and $D$, Plane of section highlights the descent of a labeled sensory tract from lobules of somata situated out of the field above. $E$, High magnification micrograph illustrating selective labeling of the fiber subpopulation; arrowheads point to glial boundary. The stimulus in $A$ to $D$ was carrot odor; in $E$ it was clean air. Scale bar: $A$ to $D, 40 \mu \mathrm{m} ; E, 32 \mu \mathrm{m}$. 

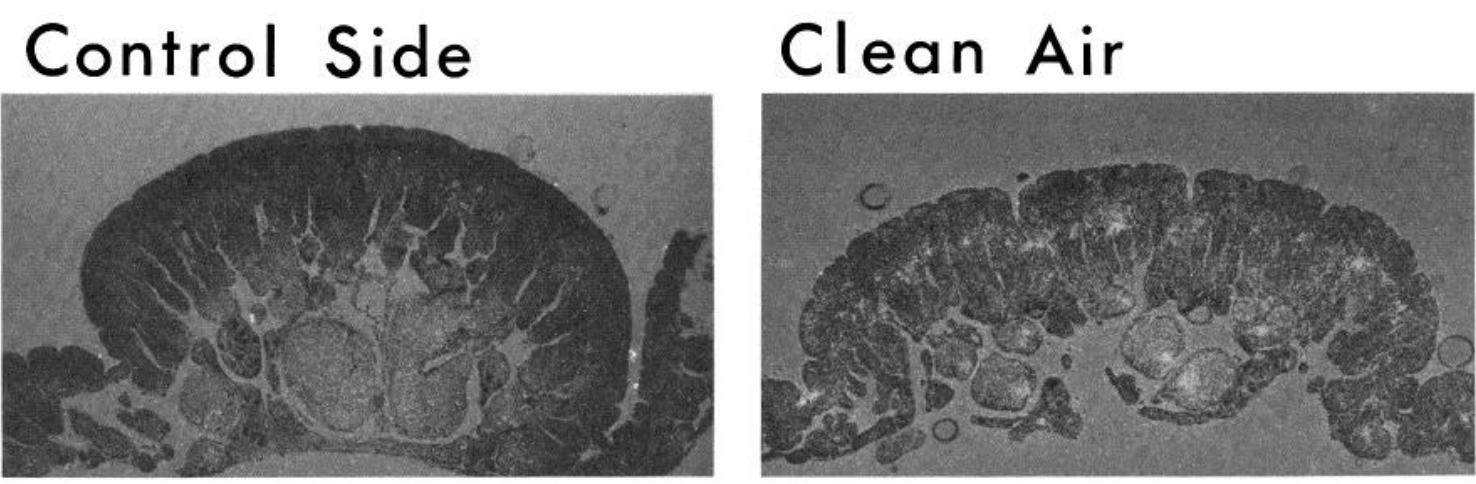

\section{Carrot}
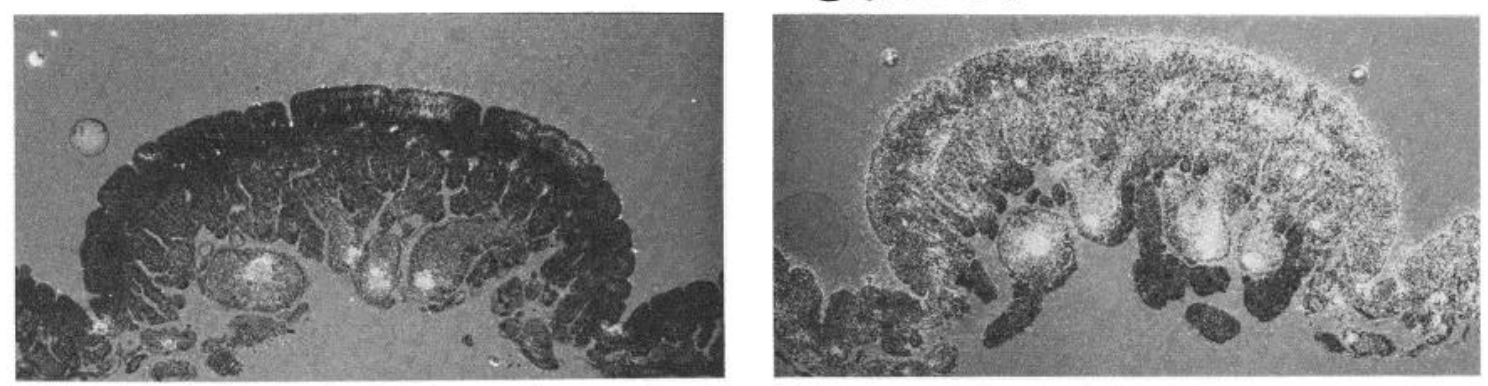

\section{Snails}
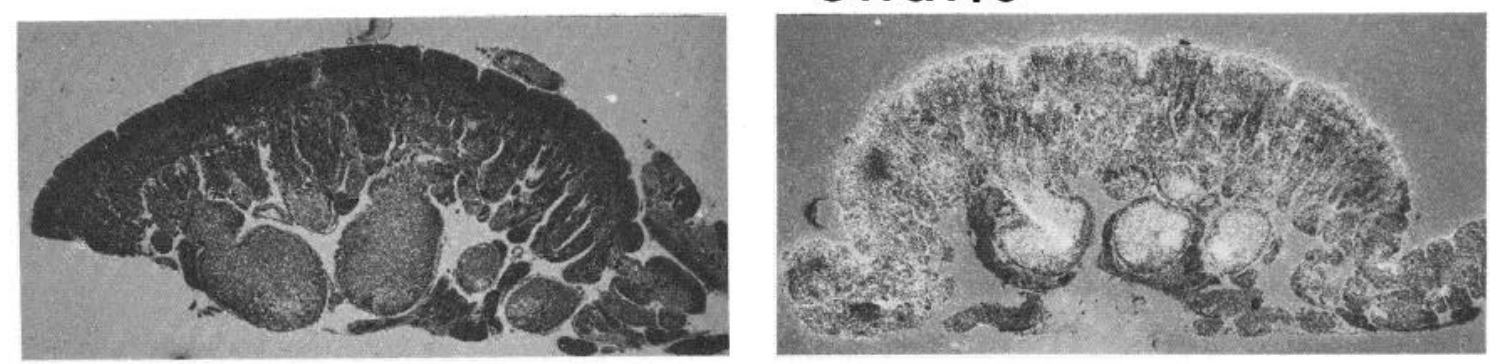

\section{Octanol}
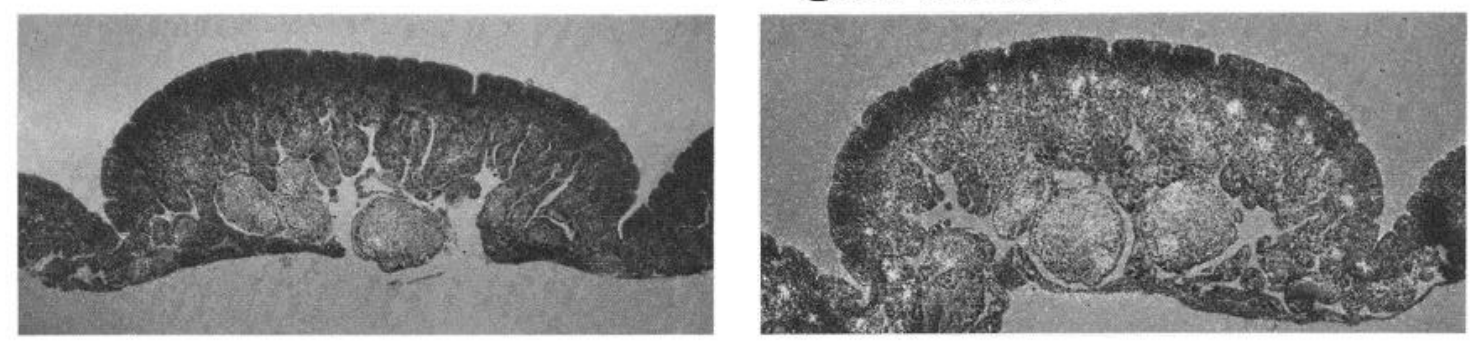

\section{Amyl Acetate}
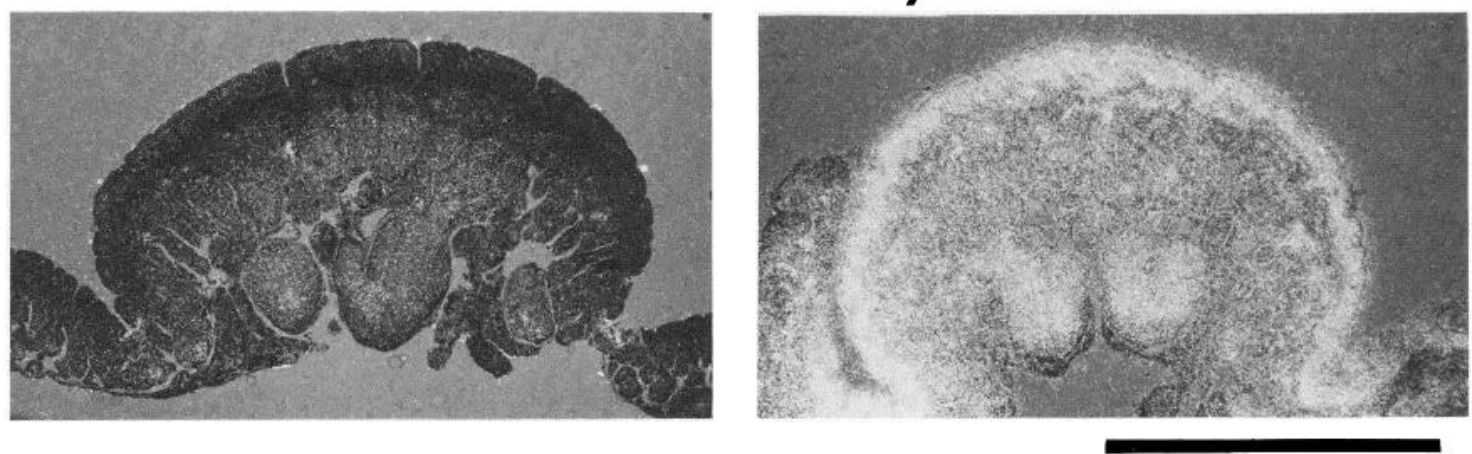

Figure 4. Patterns of 2-DG uptake in tentacle during olfactory stimulation. Left-right pairs are taken from the same animal. The left, control tentacle, was unexposed to the stimulus (sutured); the right tentacle was exposed to stimulus conditions as indicated. All micrographs are combined darkfield/brightfield images. Scale bar, $500 \mu \mathrm{m}$. 


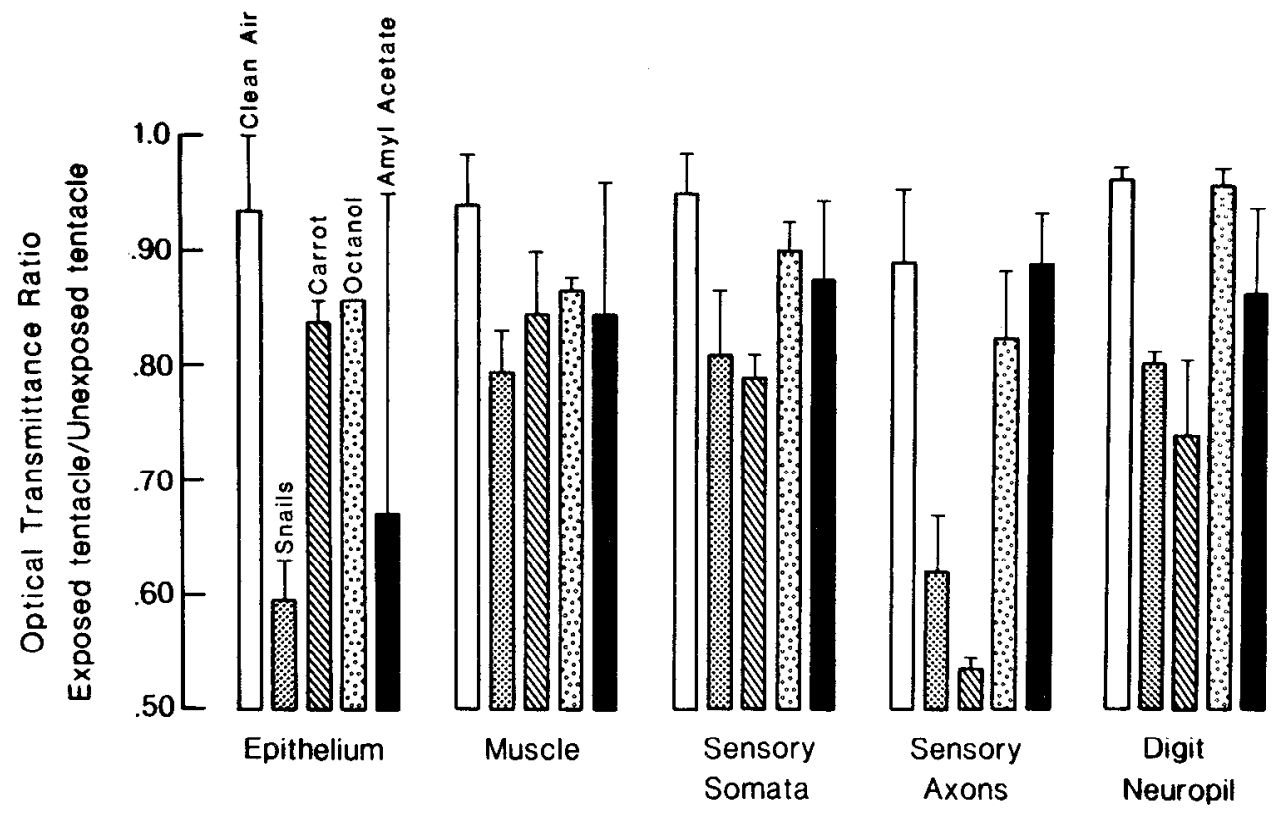

Figure 5. Ratios of optical transmittance in exposed/unexposed tentacles in relation to tissue structures and stimulus conditions. Measurements of optical density were taken at the positions shown in Figure 1. Each measurement was converted to a transmittance value, relative to the transmittance of the non-tissue background measured on the same section. Thus, high ratios indicate similar transmittances in experimental and control tentacles; low ratios indicate less transmittance (greater density) in the experimental tentacle. The histograms show the mean \pm SEM for two animals.

TABLE ॥

Number of animals in which the mean optical densily of exposed and unexposed tentacles is significantly different

The data are based on $t$ tests, with a sample of six measurements per tissue component per animal. Criterion of significance is $p<0.05$. There are a total of two animals per stimulus group.

\begin{tabular}{lcccccc}
\hline \multirow{2}{*}{ Stimulus Condition } & \multicolumn{5}{c}{ Tissue Component } & \\
\cline { 2 - 5 } & Epithelium & Muscle & $\begin{array}{c}\text { Sensory } \\
\text { Somata }\end{array}$ & $\begin{array}{c}\text { Sensory } \\
\text { Axons }\end{array}$ & $\begin{array}{c}\text { Digit } \\
\text { Nouropil }\end{array}$ \\
\hline Clear air & 1 & 1 & 1 & 1 & 0 & 4 \\
Snails & 2 & 1 & 2 & 2 & 2 & 9 \\
Carrot & 0 & 1 & 1 & 0 & 1 & 3 \\
Octanol & 0 & 0 & 0 & 0 & 0 & 0 \\
Amyl acetate & 0 & 0 & 0 & 1 & 1 & 2 \\
Totals & 3 & 3 & 4 & 4 & 4 & \\
\hline
\end{tabular}

condition. The intensities of the foci, however, were dependent on slimulus conditions, as described below.

A quantitative representation of stimulus effects is provided in Figure 5. It is evident that, for all stimulus conditions and all component measures, the exposed tentacles were more heavily labeled than were the unexposed tentacles. Also, the difference between the exposed and the unexposed tentacles was less for the clean air condition than for the odor conditions, for all measures.

The histograms of Figure 5 show that there was considerable variability both between stimulus groups and within a stimulus group. The within-group variability was particularly pronounced in the amyl acetate condition, in which one exposed tentacle was heavily labeled (see Fig. 4), whereas the second tentacle, in a different animal, was only moderately labeled. Neither observable differences between animals nor known variations in tissue treatment could account for the variability in 2-DG labeling. Among the factors contributing to large standard errors, however, were the small number of animals per group (two) and the small number of optical density measurements per tentacle (six). This latter limitation notwithstanding, there were statistically significant differences between the exposed and unexposed tentacles of a single animal in 18 of 50 tests (36\%; Table II). All five measures were sensitive to the cffects of sensory stimulation. Within-animal differences were found most frequently with the "snail" stimulus (9 of 10 tests) and least frequently with octanol (0 of 10 tests). Clean air produced significant effects for three measures in one animal and one different measure in the second animal.

TABLE III

Correlation matrix for component ratios of optical density (exposed tentacle/unexposed tentacle)

Data were pooled from five stimulus groups, two animals per group, with normalization for differences between group means.

\begin{tabular}{lccccc}
\hline & Epithelium & Misscle & $\begin{array}{c}\text { Sensory } \\
\text { Somata }\end{array}$ & $\begin{array}{c}\text { Sensory } \\
\text { Axons }\end{array}$ & $\begin{array}{c}\text { Digit } \\
\text { Neuropil }\end{array}$ \\
\hline Epithelium & 1.00 & & & & \\
Muscle & 0.98 & 1.00 & & & \\
Sensory somata & 0.83 & 0.91 & 1.00 & & \\
Sensory axons & 0.45 & 0.46 & 0.34 & 1.00 & \\
Digit neuropil & 0.47 & 0.42 & 0.52 & 0.31 & 1.00 \\
\hline
\end{tabular}

TABLE IV

Differences between pairs of stimulus groups, discriminated by the optical density of autoradiographic label overlying sensory axons

A post-hoc test of least significant differences was used. The upper value is the $F$ statistic ( 1 and $5 \mathrm{df}$ ); the lower value is probability.

\begin{tabular}{lrrrr} 
& Snails & Carrot & Octanol & $\begin{array}{c}\text { Amyl } \\
\text { Acetate }\end{array}$ \\
\hline Clear air & 14.52 & 25.07 & 0.39 & 0.83 \\
& 0.01 & 0.01 & 0.56 & 0.40 \\
Snails & & 1.43 & 10.18 & 8.11 \\
& & 0.29 & 0.02 & 0.03 \\
Carrot & & 19.24 & 16.78 \\
& & & 0.01 & 0.01 \\
Octanol & & & & 0.84 \\
& & & & 0.78 \\
\hline
\end{tabular}

Variations in stimulus quality had different effects on different components in the tentacle. Three of the components (epithelium, muscle, and sensory somata) tended to respond similarly, whereas the sensory axons and the digit neuropil were each independent of all other components (Table III). An analysis of variance showed that the stimulus groups are significantly different with respect to labeling of the sensory axons $(F$-ratio, $9.69 ; p<0.01)$, but not of any other component. The optical density of the label in the sensory axons is, by itself, sufficient to distinguish the natural odor groups (snails, carrot) from each of the remaining stimulus groups (clean air, octanol, amyl acetate; Table IV).

Stimulus-dependent labeling in the brain. The laterality of tentacle exposure was evident in the brain (cerebral ganglion) only within the 

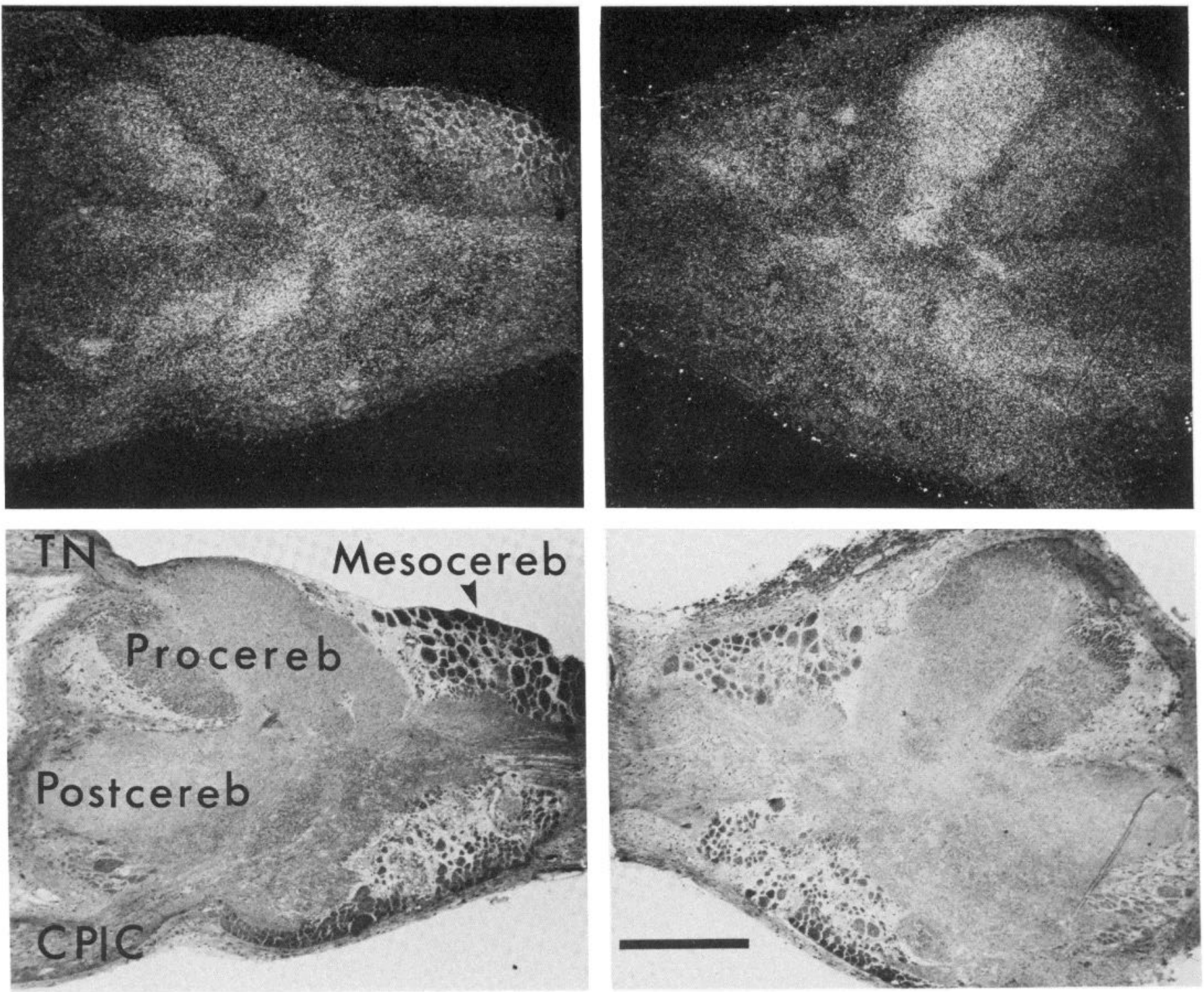

Figure 6. The brain of a snail in which the right tentacle was exposed to amyl acetate vapor, while the left tentacle was unexposed. The micrographs at the top are darkfield images of 2-DG autoradiographs; those at the bottom are brightfield. The brain was bisected to facilitate sectioning. The effect of olfactory stimulation is most evident in the procerebrum. $T N$, tentacle (olfactory) nerve; CPLC, cerebral-pleural connective. Scale bar, $300 \mu \mathrm{m}$.

region designated as procerebrum (Fig. 6). Here, the area of the ganglion cell bodies and the area of neuropil (Fig. 7) were both more heavily labeled on the exposed side than on the unexposed side. The labeling of individual cell somata could not be resolved. Although optical densities were not quantified in the brain tissue because of the uneven quality of the sections, there were no obvious differences between odor groups with respect to label distribution or density. Animals having the greatest differences in tentacular labeling tended also to have the most pronounced lateral asymmetry of procerebrum label.

\section{Discussion}

The results, taken as a whole, demonstrate that a functional neural system can be mapped in an intact invertebrate animal using 2-DG autoradiography. Some of the particular results provide new information about odor processing in the snail and offer a useful perspective on other, more thoroughly investigated olfactory systems. Before turning to a discussion of these issues, however, some comments on methodology are required. The general appearance of the autoradiographs presented here, and their resolving power, is very similar to that reported in rat and salamander, also using $\left[{ }^{14} \mathrm{C}\right]$ 2-DG and tissue processing by acetone freeze-substitution (Lancet et al., 1982). Although the degree of resolution obtained with $\left[{ }^{14} \mathrm{C}\right]$. 2-DG is less than that obtained with $\left[{ }^{3} \mathrm{H}\right]-2-D G$ (Sejnowski et al., 1980; Hammer and Herkenham, 1984), it is nonetheless adequate to resolve individually labeled sensory neurons or at least clusters of two or three such cells.

The present results are further consistent with earlier reports on vertebrates (Schwartz et al., 1979; Lund et al., 1981; Lancet et al., 1982 ) in that fibers were more heavily labeled than cell bodies. This was evident in the procerebrum, where the grain density over the neuropil was greater than over the adjacent region of cell somata, and it was most striking in the tentacle, where the axons of the sensory neurons were consistently more heavily labeled than the somata of the same cells and where stimulus effects were significantly more pronounced in the axons than in the somata (Figs. 4 and 5). Presumably, the bias in favor of fibrous processes derives from the facts that 2-DG uptake reflects the amount of energy 

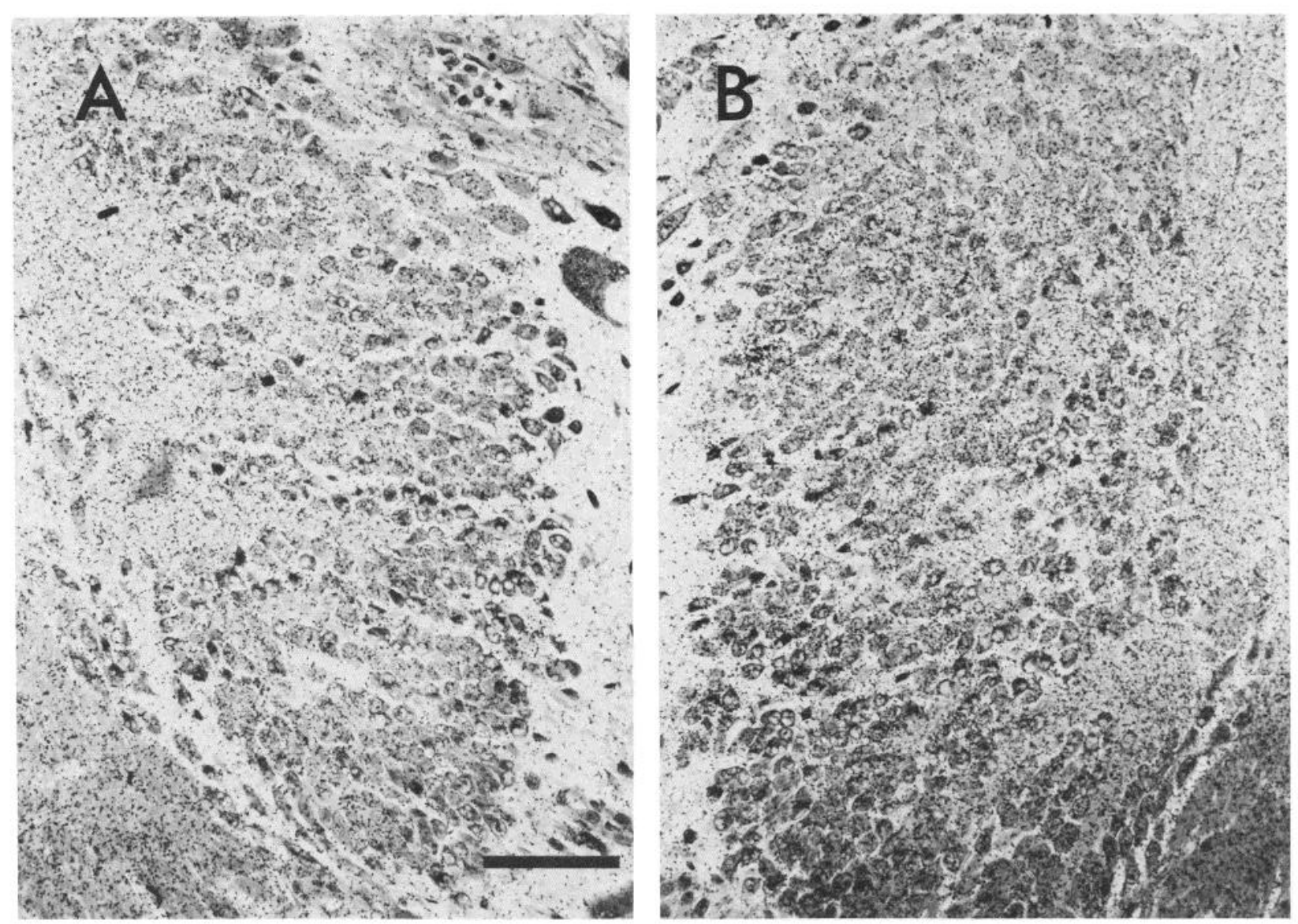

Figure 7. The effect of amyl acetate stimulation on the uptake of 2-DG by ganglion cells in the procerebrum. Equivalent regions of the left $(A)$ and right (B) hemiganglia are shown. The right tentacle only was exposed to amyl acetate. Scale bar, $50 \mu \mathrm{m}$.

required by a sodium pump (Mata et al., 1980) and that, so far as the pump activity is necessary to restore electrochemical gradients following electrical signaling, energetic demand is proportional to surface-to-volume ratios (DeWeer, 1975). In apparent contradiction to the present results, and to the preceding explanation, stand the papers by Sejnowski et al. (1980) and Reingold et al. (1981), who reported heavy labels of $\left[{ }^{3} \mathrm{H}\right]-2-D G$ over single large (about $50 \mu \mathrm{m}$ ) molluscan neurons. Their studies do not unequivocally demonstrate, however, that the labels depend on electrical activity. In similar in vitro experiments with the subesophageal ganglia of $A$. fulica, some giant neurons (about $200 \mu \mathrm{m}$ ) were heavily labeled with $\left[{ }^{14}\right] \mathrm{C}-2-D G$ under "resting" conditions, but repeated attempts to induce uptake in a given cell by intracellular stimulation of one of a matched pair of giant neurons have been unsuccessful (unpublished data).

Any interpretation of the stimulus effects in these experiments depends on the validity of the experimental design, in which one tentacle (and one hemicerebrum) in every animal served as the control for its contralateral counterpart. The control tentacle remained inside the snail, whereas the other tentacle was exposed to an air environment that was manipulated by the experimenter. It is important to note that the unexposed tentacle was maintained (by suture at the point of exit) in an entirely natural retracted position, one that is regularly adopted throughout the diurnal period of inactivity. In the present experiments, the tentacle was kept retracted for only slightly longer than the tropical day length. During unfavorable climatic seasons, when the animal estivates, the tentacles remain internal for a month or more. Moreover, the previously unexposed tentacle was found to be normal in its sensitivity to food odor immediately after re-exposure, and the histology of the unexposed tentacle was indistinguishable from that of the exposed tentacle. Nevertheless, the control tentacle can only be described as "unexposed" in relation to the experimental conditions imposed on the opposite tentacle. The internal environment of the former is unknown in detail, but surely contains potential chemical stimuli. An alternative experimental approach was therefore attempted in which, by use of a tentacular olfactometer (Chase, 1982), both tentacles were exposed to equivalent air flows, one odorized and the other unodorized. This method, however, is only practical for exposure durations of $2 \mathrm{hr}$ or less. Regrettably, then, the preliminary experiments with the olfactometer, as well as those with an in vitro preparation and the intact animal, all indicated the need for exposures of at least $4 \mathrm{hr}$. Finally, it is emphasized that, in addition to the within-animal control, the clean air trials constituted a second, between-animal control. It is significant that all five of the component measures showed a larger optical transmittance ratio in the clean air condition than in any of the odor conditions (Fig. 5). On the other hand, the finding that clean air itself produced a significant effect (Figs. 4 and 5; Tables I and II) confirms the mechanical sensitivity of the tentacle (Chase and Croll, 1981). It also makes unlikely the possibility (Price, 1984) that the effects of odorants on 2-DG uptake are the direct effects of odorous compounds on cellular metabolism, antecedent to any changes in membrane potential.

A small percentage of the sensory neurons was labeled by sensory stimulation (Table I). A surprising feature of this particular result was the localization of most of the labeled sensory neurons to the extreme upper parts of the sensory lobules. This could reflect the proximity of these cells to the dendritic sites of initial depolarization by sensory stimulation, which would result in a greater ionic flux in the somata of these cells as compared with underlying cells. Alternatively, the labeled neurons might constitute the subpopulation 
of $\beta$ sensory neurons, which are less numerous but slightly larger than the $\alpha$ sensory neurons, lie more superficially in the lobules, and can be distinguished from $\alpha$ neurons by ultrastructure (Wright, 1974) or in silver-stained preparations (Demal, 1955). Unfortunately, the histological material available in the present study did not permit a reliable distinction to be made. Nevertheless, in view of the fact that the tentacles in Achatina possess both mechanical and chemical sensitivity (Chase and Croll, 1981), it is tempting to speculate that the labeled cells are identical to the $\beta$ cells and that they are mechanosensors. Consistent with this idea was the finding that approximately as many sensory neurons were labeled by stimulation with clean air as by stimulation with odors (Table I).

The often prominent and selective labeling of the tentacular epithelium after olfactory stimulation (Figs. $2 A, 4$, and 5) merits comment in view of the current uncertainty about the role of epithelium in olfactory processes. In the vertebrate nose, the epithelial (sustentacular) cells, together with the Bowman's glands, secrete mucus onto the overlying surface where odor molecules are trapped and where transduction presumably occurs (Getchell and Getchell, 1977: Getchell et al., 1984). In the snail, also, the epithelium of the olfactory organ has a histological appearance that is clearly different from that of the adjacent, non-sensory, tentacular wall, and it contains small granules that may be secretory (Chase and Tolloczko, 1985). Because the dendrites of the sensory neurons pass through the epithelium on their way to the mucosal surface (Fig. 1), it could be that the 2-DG label in the epithelium reflects the transduction process, or electrical signaling, in the neuronal dendrites. This seems unlikely, however, because the relative optical density of the epithelial label correlates poorly with that of the sensory neuron axons (Table III). Alternatively, the epithelial label may indicate an increase in secretion elicited by the stimulus. Nathan and Moulton (1981) reported that, in the salamander, oltactory stimulation caused a selective uptake of 2-DG by Bowman's glands. These findings therefore support the idea that odors stimulate mucus secretion (Okano and Takagi, 1974) and that such secretions have a role in the transduction process (Getchell and Getchell, 1977; Price, 1984).

The stimulus-dependent labeling of the procerebrum is not unexpected given that the tentacular olfactory nerve joins the brain at this position. What is notable, however, is the large extent of the olfactory neuropil (Fig. 6). In fact, the procerebrum as a whole, neuropil plus cell bodies, constitutes about one-third of the volume of the entire brain. The cells of the procerebrum are especially interesting because they apparently possess no axon (Hanström, 1925). They are therefore unusual for a molluscan nervous system, but strikingly similar to the granule cells of the vertebrate olfactory bulb. An important task for the future is to discover the mechanisms of olfactory processing in the procerebrum.

Before considering the variations in 2-DG uptake with different odorous stimuli, it is important to emphasize that all of the odors used in this study have previously been shown to be effective in eliciting behavioral attraction to a source, at concentrations equivalent to those used here (Chase et al., 1978; Croll and Chase, 1980; Chase, 1982). In these earlier studies, octanol was slightly less attractive than amyl acetate (Chase, 1982), whereas the conspecific odor and the carrot odor were compared neither with each other nor with the pure compounds. A clear result in the present study was the superiority of the "natural" odors, of snails and carrots, in eliciting a stimulus-specific uptake of the radiolabel. (Figs. 4 and 5; Tables II and IV). One explanation for this finding is that the snail odor and carrot odor are both mixed odors, containing multiple chemical constituents. Consequently, they might be expected to excite more neural units than the odors composed of single compounds. Alternatively, the natural odors, but not the pure odors, were familiar to the snails from past experience and, for this reason alone, they could be expected to carry a greater behavioral significance (Croll and Chase, 1980). In rats, where some behaviorally important olfactory cues are also recognized on the basis of experience, the familiar olfactory stimuli elicit an enhanced neural re- sponse, as measured by 2-DG autoradiography (Coopersmith and Leon, 1984).

The search for spatial differences in 2-DG uptake as a function of odor quality yielded no positive results. By contrast, in the vertebrate olfactory system the use of the same $\left[{ }^{14} \mathrm{C}\right]-2-D G$ methodology, or even the less precise film autoradiography, has provided ample evidence of spatial coding (Stewart et al., 1979; Jourdan et al., 1980; Nathan and Moulton, 1981; Lancet et al, 1982). The hypothesis of a spatial code for odor quality was tested most strongly at the level of the sensory neuron axons. It is here that the 2-DG label was most intense, and it was at this level that the stimulus effects were the most pronounced. Also, the morphology of the receptors in the snail, as well as their disposition in a pseudo-stratified columnar epithelium (Demal, 1955; Wright, 1974; Chase and Kamil, 1983; Chase and Tolloczko, 1985; Fig. 1), is strikingly similar to the vertebrate counterparts ( $R$. Chase, manuscript in preparation). In vertebrates, there is good evidence for a nonhomogeneous distribution of receptor types in the epithelium (Kauer, 1980) and a corresponding dependency of 2-DG spatial patterns on the quality of an odor stimulus (Nathan and Moulton, 1981). The experiments reported here, however, fail to provide similar evidence in the snail. Furthermore, in neither the tentacle ganglion nor the procerebrum, both of which might be considered analgous to the vertebrate olfactory bulb as terminal sites for primary olfactory afferents, is there evidence for a spatial code. It must be emphasized, however, that the details of structure and function in the gastropod olfactory system are still largely unknown. Also, a study of the system using 2-DG methods of even higher resolution (e.g., $\left.\left[{ }^{3} \mathrm{H}\right]-2-D G\right)$, and more automated analytical procedures, could yet reveal a spatial code.

In contrast to the gastropod olfactory system, as presently understood, the insect olfactory system seems to share with its vertebrate counterpart a design according to which odor qualities are spatially distributed. Thus, the insect olfactory system has prominent glomeruli (in the antennal lobes) and these appear to be functionally differentiated (Rodrigues and Buchner, 1984). One identifiable glomerulus (or glomerular complex) is specialized for pheromone odors (Matsumoto and Hildebrand, 1981), analgous to the glomerular region in the rat olfactory bulb that is apparently specialized for perception of suckling pheromone (Teicher et al., 1980). If the gastropod olfactory system lacks a spatial code, this would demonstrate that spatial coding, although widespread, is neither a universal feature nor an essential feature of olfactory information processing.

\section{References}

Alexander, J., Jr., T. E. Audesirk, and G. J. Audesirk (1983) One-trial reward learning in the snail Lymnea stagnalis. J. Neurobiol. 15: 67-72.

Buchner, E., and S. Buchner (1983) Anatomical localization of functional activity in flies using ${ }^{3} \mathrm{H}$-2-deoxyglucose. In Functional Neuroanatomy, $\mathrm{N}$. J. Strausfeld, ed., pp. 225-238, Springer-Verlag, Berlin.

Buchner, E., S. Buchner, and R. Hengstenberg (1979) 2-Deoxy-D-glucose maps movement-specific nervous activity in the second visual ganglion of Drosophila. Science 205: 687-688

Chase, R. (1982) The olfactory sensitivity of snails, Achatina fulica. J. Comp. Physiol. 148: 225-235

Chase, R., and R. P. Croll (1981) Tentacular function in snail olfactory orientation. J. Comp. Physiol. 143: 357-362

Chase, R., and R. Kamil (1983) Neuronal elements in snail tentacles as revealed by horseradish peroxidase backfilling. J. Neurobiol. 14: 29-42.

Chase, R., and B. Tolloczko (1985) Secretory glands of the snail tentacle and their relation to the olfactory organ. Zoomorphology 105: 60-67.

Chase, R., K. Pryer, R. Baker, and D. Madison (1978) Responses to conspecific chemical stimuli in the terrestrial snail Achatina fulica. Behav. Biol. 22: 302-315.

Coopersmith, R., and M. Leon (1984) Enhanced neural response to familiar olfactory cues. Science 225: 849-851.

Croll, R. P. (1983) Gastropod chemoreception. Biol. Rev. 58: 293-319.

Croll, R. P., and R. Chase (1980) Plasticity of olfactory orientation to foods in the snail Achatina fulica. J. Comp. Physiol. 136: 267-277. 
Demal, J. (1955) Fssai d'histologie comparée des organes chémorécepteurs des gastéropodes. Mém. Acad. R. Belg. 29: 1-88.

DeWeer, P. (1975) Aspects of the recovery process in nerve. In Physiology. Series I, Vol. 3: Neurophysiology, C. C. Hunt, cd., pp. 231 278, Butterworth, London.

Getchell, T. V., and M. L. Getchell (1977) Histochemical localization and identification of secretory producls in salamander olfaclory epithelium. In Olfaction and Taste, J. Le Magnen and P. Macleod, eds., Vol. 6, pp. 105112, IRL Press, London.

Getchell, M. L., J. A. Kafols, and I. V. Getchell (1984) Histological and histochemical studies of the secretory components of the salamander olfactory mucosa: Effects of isoprotental and olfactory nerve section. Anat. Rec. 208: 553-565.

Hammer, R. P., Jr., and H. Herkenham (1984) Tritiated 2-deoxy-D-glucose: A high-resolution marker for autoradiographic localization of brain metabolism. J. Comp. Neurol. 222: 128-139.

Hanström, B. (1925) Uber die sogenannten Intelligenzsphären des Molluskengehirns und die Innervation des Tentakels von Helix. Acta Zool. Stockh. 6: $183-215$.

Jourdan, F., A. Duveau, L. Astic, and A. Holley (1980) Spatial distribution of $\left[{ }^{14} \mathrm{C}\right]-2$-deoxyglucose uptake in the olfactory bulbs of rats stimulated with two different odours. Brain Res. 188: 139-154.

Kauer, J. S. (1980) Some spatial characteristics of central information processing in the vertebrate olfactory pathway. In Olfaction and laste, $\mathrm{H}$. van der Starre, ed., Vol. 7, pp. 227--236, IRL Press, London.

Lancet, D., C. A. Greer, J. S. Kauer, and G. M. Shepherd (1982) Mapping of odor-related neuronal activity in the olfactory bulb by high-resolution 2 deoxyglucose autoradiography. Proc. Natl. Acad. Sci. U. S. A. 79: 670674.

Lund, J. P., J. J. Miller, and J. Courville (1981) [ $\left.{ }^{3} \mathrm{H}\right]-2$-Deoxy-D-glucose capture in the hippocampus and dentate gyrus of ketamine-anesthetized rat. Neurosci. Lett. 24: 149-153.

Mackay-Sim, A., and J. L. Kubie (1981) The salamander nose: A model system for the study of spatial coding of olfactory quality. Chem. Sens. 6 . 249-257.

Mata, M., D. J. Fink, H. Gainer, C. B. Smith, L. Davidsen, H. Savaki, W. J. Schwartz, and L. Sokoloff (1980) Activity-dependent energy metabolism in rat posterior pituitary primarily reflects sodium pump activity. J. Neurochem. 34: 213-215.

Matsumoto, S. G., and J. G. Hildebrand (1981) Olfactory mechanisms in the moth Manduca sexta: Response characteristics and morphology of central neurons in the antennal lobes. Proc. R. Soc. Lond. (Biol.) 213: 249-277.

Nathan M. H., and D. G. Moulton (1981) 2-Deoxyglucose analysis of odorant- related activity in the salamander olfactory epithelium. Chem. Sens. 6 : $259-265$.

Okano, M., and S. F. Takagi (1974) Secretion and electrogenesis of the supporting cell in the olfactory epithelium. J. Physiol. (Lond.) 242: 353370

Pawson, P. A., and R. Chase (1984) The life-cycle and reproductive activity of Achatina fulica (Bowditch) in laboratory culture. J. Moll. Stud. 50: 8591.

Plum, F., A. Gjedde, and F. E. Samson (1976) Neuroanatomical functional mapping by the radioactive 2-deoxy-glucose method. Neurosci. Res. Program Bull. 14: 456-518.

Price, S. (1984) Mechanisms of stimulation of olfactory neurons: An essay Chem. Sens. 8: 341-354.

Reingold, S. C., T. J. Sejnowski, A. Gelperin, and D. B. Kelly (1981) $\left[{ }^{3} H\right]-2-$ Denxyglucose autoradingraphy in a molluscan nervous system. Brain Res 208: 416-420.

Rodrigues, $\mathrm{V}$., and E. Buchner (1984) [ $\left.{ }^{3} \mathrm{H}\right] 2$-Deoxyglucose mapping of odorinduced neuronal activity in the antennal lobes of Drosophila molanogastor. Brain Res. 324: 374-478.

Sahley, C. L., A. Gelperin, and J. Rudy (1981) One-trial learning modifies food odor preferences of a terrestrial mollusc. Proc. Nall. Acad. Sci. U. S A. $78: 640-642$.

Schwartz, W. J., C. B. Smith, L. Davidson, H. Savaki, L. Sokoloff, M. Mata D. J. Fink, and H. Gainer (1979) Metabolic mapping of functional activity in the hypothalamoneurohypophyseal system of the rat. Science 205: $723-725$

Sejnowski, T. J., S. C. Reingold, D. B. Kelly, and A. Gelperin (1980) Localization of $\left[{ }^{3} \mathrm{H}\right]$-2-deoxyglucose in single molluscan neurones. Nature 287: 449-451.

Sharp, F. R., T. S. Kilduff, and H. C. Heller (1981) The 2-deoxyglucose neuroanatomical mapping technique. Trends Neurosci. 4: 144-147.

Stewart, W. B., J. S. Kauer, and G. M. Shepherd (1979) Functional organi zation of rat olfactory bulb analyzed by the 2-deoxyglucose method. $\mathrm{J}$ Comp. Neurol. 185: 715-734

Teicher, M. H., W. B. Stewart, J. S. Kauer, and G. M. Shepherd (1980) Suckling pheromone stimulation of a modified glomerular region in the developing rat olfactory bulb revealed by the 2-deoxyglucose method Brain Res. 194: 530-535.

Wei, A. (1983) Identification of active single neurons in locust neural circuits using $\left[{ }^{3} \mathrm{H}\right]-2$-deoxyglucose autoradiography. Soc. Neurosci. Abstr. 9: 540

Wright, B. R. (1974) Sensory structure of the tentacles of the slug, Arion ater. I. Ultrastructure of the distal epithelium, receptor cells and tentacular ganglion. Cell Tissue Res. 151: 229-244. 